\title{
Magmatic process related to the formation of Fe-Ti oxide deposits in the Panxi region, SW China
}

\author{
KUN WANG ${ }^{1}$, HUAN DONG ${ }^{2}$ AND RUI LIU ${ }^{3}$ \\ ${ }^{1}$ China University of Mining and Technology \\ ${ }^{2}$ Yangtze University \\ ${ }^{3}$ Shandong University of Technology \\ Presenting Author: kunwang89@126.com
}

Several giant Fe-Ti oxide deposits such as the Panzhihua, Hongge, Baima, and Taihe, are hosted in ca. 260 Ma maficultramafic layered intrusions in the Panxi region, SW China. These intrusions are unique in that they contain large proportions of massive ores within the relatively small bodies. How Fe-Ti oxides are concentrated has long been controversial with two main views of fractional crystallization and liquid immiscibility. In fact, fractional crystallization is a definite process in any magma differentiation processes, and whether liquid immiscibility was involved in the formation of oxide ores is the core of the debate. In our study, we find that apatite-hosted melt inclusions of the ore-bearing intrusions deviate from the possible liquid lines of descent calculated by MELTS thermodynamic algorithm [1]. This is difficult to be explained by fractional crystallization but can be ascribed to liquid immiscibility. The compositional zonings and reaction rims of cumulus plagioclases are considered to indicate the effective separation of immiscible liquids. We think that the upwards-expulsed Si-rich melts may have been remixed with the upper main magma body or formed the felsic veins/lens in these ore-bearing intrusions. Large amount of Fe-Ti oxides crystallized from the residual Fe-rich melts and formed the main ore bodies of the layered intrusion in the Panxi region.

[1] Ghiorso \& Sack (1995) Contrib Mineral Petr 119(2), 197212. 